\title{
Characterization of the impact on the society of the local cisco networking academy of ITSA in Barranquilla
}

\author{
Leonel Hernandez ${ }^{\mathrm{a}, 1,{ }^{*}}$, Piedad Marchena ${ }^{\mathrm{a}, 2}$, Aji Prasetya Wibawa ${ }^{\mathrm{b}, 1}$ \\ ${ }^{a}$ Instituciòn Universitaria ITSA, Carrera 45 \# 48 -31, Barranquilla, Colombia \\ ${ }^{\mathrm{b}}$ Department of Electrical Engineering, Universitas Negeri Malang, Malang, Indonesia \\ ${ }^{1}$ lhernandezc@itsa.edu.co*; ${ }^{2}$ pmarchena@itsa.edu.co; ${ }^{3}$ aji.prasetya.ft@um-ac.id
}

\begin{tabular}{l} 
AR TICLE IN FO \\
\hline Article history \\
Received January 3, 2020 \\
Revised January 17, 2020 \\
Accepted February 1,2020 \\
Keywords \\
Cisco \\
Networking \\
Academy \\
Feedback \\
Propedeutic \\
Students
\end{tabular}

By 1997, Cisco Systems, a company already consolidated in the technology and communications market, saw the need to train personnel who had the skills to configure, manage, install and support all its products in general at all levels, from design to the implementation of solutions. In Colombia, more precisely in the city of Barranquilla, the ITSA University Institution in the early 2000s saw an excellent opportunity to ally with the University created by Cisco, called Cisco Networking Academy, to train professionals in the Caribbean region capable of face the new challenges that technology in networks is generating day by day, becoming in the first Institution of higher education in the region to provide this type of training with international certification and endorsement. From then on, the local Cisco academy has strengthened and significantly impacted local society, generating valued and skilled labor in the labor market of the city and the region. The purpose of this work is to measure this impact, focused on the Cisco, CCNA, and CCNP flagship courses between 2017 and 2019. To fulfill the purpose of the study, two types of research have been used according to the object of study, exploratory and documentary research. According to the level of measurement, scientific knowledge and analysis of the information, the research is quantitative and descriptive. The research design is non-experimental longitudinal, using the Cisco satisfaction survey as a measurement instrument to collect data and analyze the information. As a result, the study shows the high level of satisfaction of the students of the academy in the points analyzed throughout the defined period, which allows us to conclude the positive impact that training under the Cisco methodology has had on society.

\section{Introduction}

ITSA (University Institution ITSA) is an institute of higher education in the department of Atlántico committed to providing the best learning opportunities to our student community. The University offers several academic degrees by tiered vocational cycles to meet the needs of the Caribbean Region's industrial and social sectors in a global context. ITSA started working in 2000; one of its primary goals has been to promote the usage of Information and Communication Technologies. It has also been a pioneer in partnering with the technology education program Cisco Networking Academy. ITSA has led campaigns to implement and articulate high school and college workforce education programs. Furthermore, ITSA has taken steps to bring education to those who live far away from cities. ITSA has been recognized as having set forth a proactive and successful educational pattern to be followed [1].

In Latin America, the demand for professionals with ICT skills will exceed the supply, and it will take 449,000 full-time employees by 2019, according to the Study on Network Skills in Latin 
America, commissioned by Cisco to the company IDC. In Mexico, the shortage will reach 148,052 employees for the same year. This gap causes companies and governments to face the challenge of finding professionals with the right skills that allow them to drive innovation to be globally competitive. The same study suggests that Latin America is advancing on the path to transformation through the adoption of technology and innovation, which increases competitiveness in the world and solves its unique challenges. Some of the technological trends in Latin America worth highlighting are Cloud computing, open-source and network disaggregation, software-defined networks behind the transformation, the dominance of network security, convergence and integration of communication and collaboration unified to business and mobility, the rise of medium-sized companies in the adoption of technologies in Latin America. Undoubtedly, the teaching-learning process is changing to adapt to the digital revolution, as expressed by [2] in their study, in which they highlight that the digital revolution has created a vast space of interconnected information and communication, in the Which take as an example the curricula of the Networking Academy of Cisco, to exemplify the impact that this educational model has caused in society.

The ITSA University Institution, a pioneer in the implementation of the propedeutic cycle model, it is characterized by being a proactive Institution, committed to the constant development and improvement of higher education in the Caribbean Region and the country. To accomplish this, the ITSA University Institution has the laboratories required to properly develop the contents of the different modules, and Pearson Vue, which is one of the international organizations for the certification of technical and technological competences of Cisco, among others. It also has instructors recognized by the academy to carry out training in the administration of telematics services in the area of data networks.

According to the studies carried out by the Cisco Academy, the need for management and administration in the different services of data networks, communications and computers are evident, considering the interconnection of people, processes, data, and things, which will create an impact sustainable in every aspect of society. Both the undergraduate students of the Telematic Engineering program, and the students of the Institution's Extension programs focused on the area of computer networks, have access to the Netacad platform of Cisco Academy, in which the material in line of different Cisco courses, translated in several languages [3].

A differentiating factor of the ITSA University Institution programs concerning other similar programs in the preparation in computer networks is the inclusion of the training programs provided through the Cisco academy within the training cycles, with which It is prepared for the presentation of the international certification exams in this area, which is highly requested by the productive sector. However, until now, a characterization has not been carried out in which the impact of the formation of the Cisco Networking Academy in our environment is estimated. It is necessary to carry out this analysis to focus on efforts that are aimed at increasing the satisfaction indicators of both students and representatives of the productive sector concerning graduates.

The rest of the document will deal with the following points. A review of the literature with similar studies is made. The research methodology will be described, specifying the method of information collection, to later show the results and analyze the leading satisfaction indicators of recent years, focused on the CCNA and CCNP training (main products of the full offer of the Cisco Networking Academy, which are the most requested). Finally, the recommendations for the improvement of the training process will be given, and some acknowledgments that the Institution has had by Cisco will be exposed.

\section{Literature Review - Previous Works.}

The strong impact that the programs of the Cisco academy have had in his combined model of distance learning, implemented in the Open University of the United Kingdom, highlighting the importance of the model above for supporting students in their process Learning [4]. Another study present an investigation in which they highlight the ease of understanding and understanding in the subject of computer networks provided by the packet Tracer simulator that can be studied through the Cisco academy [5]. They emphasize that the tool allows presenting the various case studies and exercises educationally, increasing the level of student learning, improving the results of the evaluation process. 
A similar study highlighted that traditional education can be implemented as an auxiliary teaching method, to make way for new strategies such as flipped classroom and gamification, which can be achieved through education [6]. Provided by Cisco Networking Academy, with excellent results in the teaching-learning process a study in the same sense was carried out [7]. On the other hand, the effects of the different qualities of teachers on the performance of students in secondary schools with a standards-based curriculum that is offered in a blended learning environment, for which they use the Cisco Networking Academy Curriculum [8]. A comparison between assessmentbased learning and game-based learning in their research [9]. The authors created a game on the Packet Tracer simulator to be analyzed considering defined categories throughout the study. Another use of the Packet Tracer offered by Cisco Networking Academy, this time to be integrated with a Moodle platform to put knowledge into practice, validate skills and improve the teaching-learning process in general by students, is presented by [10].

A case study on teaching network engineering in conjunction with interactive learning resources offered by the Cisco Networking Academy [11]. The main goal of this work is allowing learners and educators to perform network simulations within a web browser or an interactive eBook by using any type of electronic device. A case study in which they describe all the activities carried out to offer distance learning in an open University, through Cisco programs [12]. The authors present the results of the learning process, both through face-to-face and distance learning, highlighting the indicators obtained with the latter method.

A comprehensive study on the impact of high school principal's technology leadership on the sustainability of corporate-sponsored information communication technology curriculum, in which he conducted qualitative research based on a case study from the Cisco Networking Academy in Montana [13]. The results of the study helped to develop factors that described the sustainability of corporate-sponsored ICT curricula in Montana high schools. Similar work was produced in which authors further investigate the applicability of the Cisco Networking Academy Program's instructional model for the delivery of end-user information security instructional content, planned with the assistance of Bloom's taxonomy [14]. The results of the inclusion of the Cisco Networking Academy in their training programs in Slovakia, which were positive [15].

One of the factors that have the most impact on the correct delivery of the Cisco Academy curriculum, and which is vital for the success of the program, is the infrastructure of the physical laboratories. In this sense, the impact of the FORGE toolkit, which takes advantage of the laboratory infrastructures to facilitate the development of e-learning materials [16]. Another research measured the impact of the Cisco Networking Academy on higher education programs in Malaysia [17]. Another job similar to the previous one but in Slovakia, in the country`s vocational education system [18]. A fascinating work in which they evaluate the effectiveness of the Cisco Networking Academy Program in developing countries for the preparation of future professionals in the ICT area [19]. The social responsibility of the cisco academy program is shown, highlighting that this training model can contribute positively to the transformation of lives for many people [20]. Finally, and in the same line of research work that is being carried out, presents the results of the performance and level of student satisfaction concerning the Cisco Academy curriculum, through a descriptive research methodology [21].

\section{Method}

This detailed study will be developed using the documentary and descriptive research methodology, since for the elaboration of this project it is necessary to consult a series of documents and collect information through data collection techniques, to reinforce concepts and terms in the different stages in the optimal development of the object of study. The type of research design to be used is the quantitative/longitudinal one since it is going to analyze the level or current state of variables that will be defined throughout the work and its relation [22]. The objective of having defined this research design is to analyze what is the level or state of one or several variables (collected through the measurement instrument, the Cisco survey) at various points in time (measurements years 2017, 2018 and 2019). A population has been chosen from a sample, following statistical criteria to be deepened in the project, to use data collection techniques such as direct observation and in-depth interviews, to subsequently make a qualitative analysis of the data [23]. Fig. 1 shows the stages of the project and the resources used to carry out the study: 


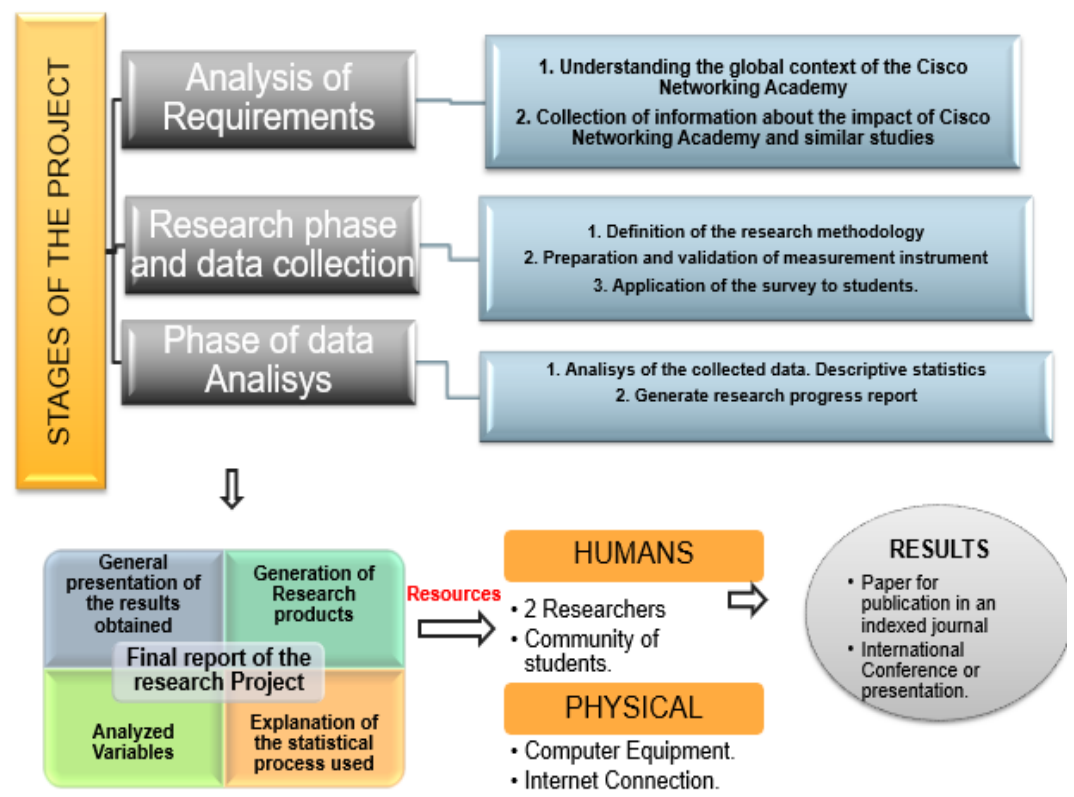

Fig. 1.Stages of the Project

The type of longitudinal non-experimental research design like the one of the study focuses on the analysis of reality in its natural dynamics. The objective is not to create situations to observe what changes in the environment from the created situation, but to describe, explain and predict reality from an approach to its natural dynamics. Longitudinal studies have the advantage that they provide information on how variables and their relationships evolve over time.

\section{Results and Discussion}

\subsection{Portfolio of programs offered by the ITSA - Cisco Networking Academy}

Table 1 shows the list of some programs offered by the local Cisco Networking Academy ITSA. All these courses are in force and are part of the curricular structure of the undergraduate engineering programs and extension graduates.

Table 1.

List of Cisco Programs

\begin{tabular}{cc}
\hline Program & Modules \\
\hline CCNAv7 & CCNA1: Introduction to Networks \\
CCNA Security & CCNA2: Switching, Routing and Wireless Essentials \\
IT Essentials & CCNA Security \\
Introduction to IoT & PC Hardware and Software \\
Entrepreneurship & Introduction to IoT \\
Introduction to Cybersecurity & Entrepreneurship \\
CCNP & Introduction to Cybersecurity \\
& CCNP Route: Implementing IP Routing \\
Linux & CCNP Switch: Implementing IP Switching \\
& CCNP Tshoot: Maintaining and Troubleshooting IP Networks \\
NDG Linux Essentials \\
Introduction to Packet Tracer & NDG Linux I \\
Partner PCAP & NDG Linux II \\
& Cybersecurity Essentials \\
\hline
\end{tabular}




\subsection{Metrics, or Key Indicators Of Success}

The local ITSA Cisco Academy has historically focused on CCNA and CCNP training. Although all the listed courses are taught, the most representative courses and the most significant number of students are in the courses. The study focuses on this sample. Likewise, the following metrics are considered as key indicators of success at our local academy. These metrics have been selected based on research and requirements defined by the NetAcad community:

- Pass Rate is the number of registrants (=registered students) who pass a course over the total number of registered students that showed activity

- Student Feedback is based on the Course Feedback surveys completed by students at the end of each class. For the feedback to be visible, three or more students must have completed the survey. Ratings derived from course feedback include: (a) Equipment Access- the quality and availability of lab equipment, (b) Instructor Rating - effectiveness of the class instructor, (c) Lab Effectiveness - the usefulness of lab exercises in learning skills, and (d) Value to Studentsrelevance of the course to students' lives

- Student Performance is based on the assessment results of students. The Academy Success Dashboard displays two informations which are final exam and gradebook score. Final Exam is the average of all students' last attempts on the Final Exam. The dashboard reflects the scores of the exams as submitted by the students - changes made by the instructors afterward in the gradebook are not considered. Gradebook Score reflects the final gradebook score. Ungraded assignments and assignments that are not completed on netacad.com are assigned a score of zero (0).

Table 2 shows the survey questions, which are applied by the Cisco academy to monitor the quality of all its courses.

Table 2.

Cisco Networking Academy - Survey

\begin{tabular}{|c|c|c|}
\hline Question & Description & Values \\
\hline Q1 & $\begin{array}{c}\text { Please rate your level of satisfaction with the following aspects } \\
\text { of this course: } \\
\text { Labs } \\
\text { Access to Equipment / Software } \\
\text { Classroom Instruction } \\
\text { Online Curriculum Materials: } \\
\text { This course as a whole } \\
\text { Assessments (including quizzes, chapter exams, and the final } \\
\text { exam) }\end{array}$ & $\begin{array}{l}\text { Very Dissatisfied } \\
\text { Dissatisfied } \\
\text { Neutral } \\
\text { Satisfied } \\
\text { Very Satisfied }\end{array}$ \\
\hline Q2 & $\begin{array}{l}\text { Please rate your confidence with the overall skills you learned in } \\
\text { this course }\end{array}$ & $\begin{array}{l}\text { Not at all confident } \\
\text { A little confident } \\
\text { Confident } \\
\text { Very confident } \\
\text { Completely confident } \\
\text { Prefer not to answer }\end{array}$ \\
\hline Q3 & $\begin{array}{l}\text { Please rate how confident you feel in your ability to do each of } \\
\text { the following: } \\
\text { *This option varies depending of the course, for example, if the } \\
\text { course is CCNA3, one option is Configure, verify and } \\
\text { troubleshoot IPv4 and IPv6 ACLs }\end{array}$ & $\begin{array}{l}\text { Not at all confident } \\
\text { A little confident } \\
\text { Confident } \\
\text { Very confident } \\
\text { Completely confident } \\
\text { Prefer not to answer }\end{array}$ \\
\hline Q4 & $\begin{array}{c}\text { Compare your instructor to other instructors you have had in } \\
\text { terms of: } \\
\text { Preparedness to teach the course } \\
\text { Clear and easy to understand lessons } \\
\text { Presenting information in multiple ways } \\
\text { Making the topic interesting } \\
\text { Approachability with questions and ideas }\end{array}$ & $\begin{array}{l}\text { Among the worst } \\
\text { A little worst } \\
\text { About the same } \\
\text { A little better } \\
\text { Among the best } \\
\text { Prefer not to answer }\end{array}$ \\
\hline Q5 & $\begin{array}{l}\text { Please rate how much you agree with the following statements } \\
\text { about your instructor(s): } \\
\text { I would take another course from this instructor. } \\
\text { I learned a lot from this instructor } \\
\text { This instructor emphasized learning through practice (such as }\end{array}$ & $\begin{array}{l}\text { Strongly disagree } \\
\text { Disagree } \\
\text { Neither Agree nor Disagree } \\
\text { Agree } \\
\text { Strongly Agree }\end{array}$ \\
\hline
\end{tabular}




Question
hands-on labs, Packet Tracer, NetLab, etc.)
Please rate how much you agree with the following statements:
Overall, the online course materials were of high quality
The hands-on lab activities helped me to achieve the stated
course objectives
Having access to equipment in the classroom helped me learn.
The online chapter quizzes helped to prepare me for the chapter
exams
Interactive activities helped me learn
Packet Tracer activities helped me learn

Rate the reading level of this course

Please rate how easy it is for you to access the course materials online from home

To what extent did this course help you:

Prepare for the Certification exam(s)

Q14

\author{
Values \\ Prefer not to answer \\ Strongly disagree \\ Disagree \\ Neither Agree nor Disagree \\ Agree \\ Strongly Agree \\ Don't know/Not Applicable
}

Much too hard

Slightly too hard

About right

Slightly too easy

Much too easy

Don't know/Not Applicable

I can't access the online course materials from home

Difficult

Somewhat Difficult

Fairly Easy

Easy

I don't have access to a computer in my classroom

I have to share my computer with more than one other person

I share my computer with one other person

I have my computer to work on during class

I don't have access to equipment in my classroom

I have to share the equipment with more than one other person

I share the equipment with one other person

I have my own equipment to work on during class

Not at all motivated

Slightly motivated Motivated

Very motivated

Completely motivated

Not at all enthusiastic

Slightly enthusiastic enthusiastic

Very enthusiastic

Completely enthusiastic

Not at all interested

Slightly interested interested

Very interested

Completely interested

Not at all

A little

Somewhat

Quite a bit

Very much

Don't know/NA 


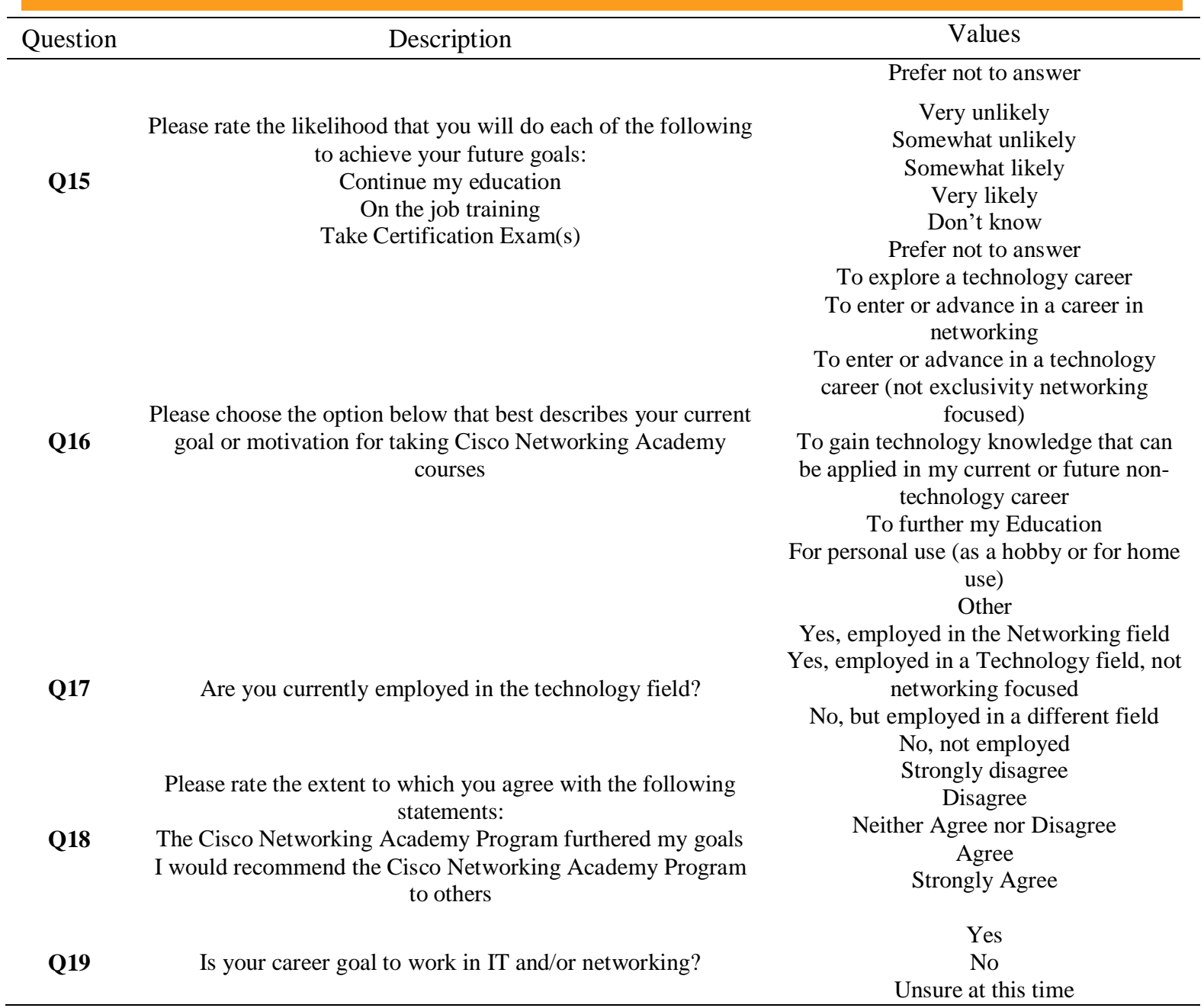

\subsection{Analysis of the results.}

Below are the results of the analysis of the survey, considering the years 2017 to 2019, for the CCNA and CCNP curricula, with the success metrics indicated above. Fig. 2 shows the pass rate, in which the CCNP pass rate is higher than CCNA, and that the best year was 2018. Pass Rate is the percentage of all students with activities at an academy who received a "Pass" in classes within the selected curriculum that ended in the selected period:

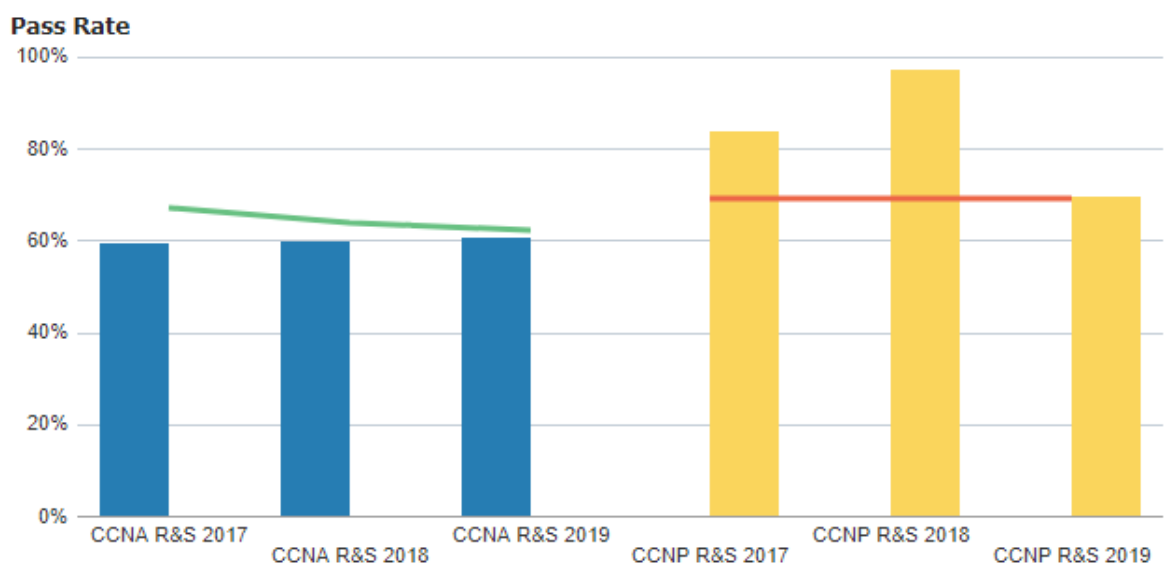

Fig. 2.Pass Rate for CCNA and CCNP 


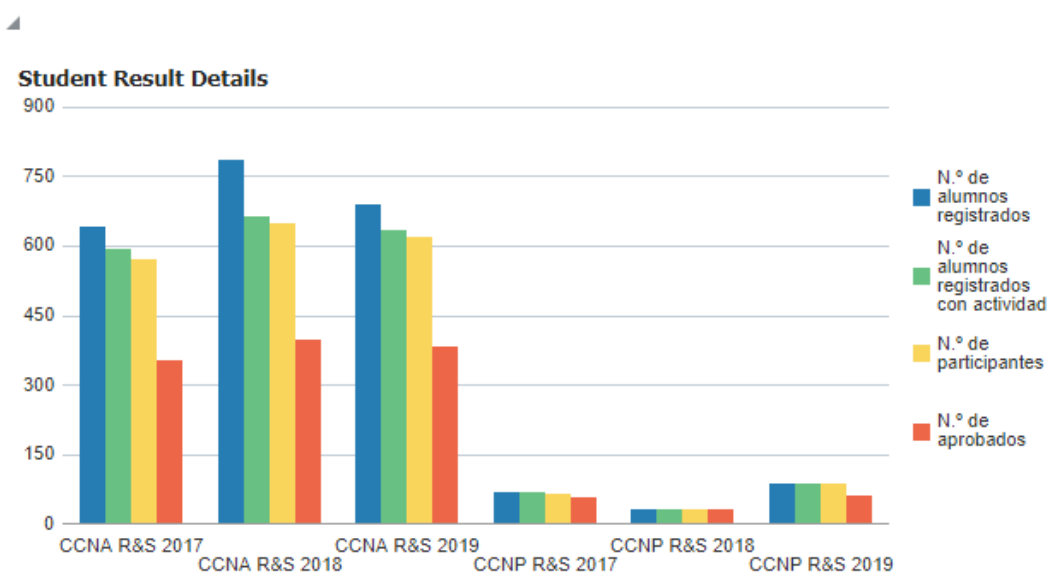

Fig. 3.Student Result Details

Fig. 3 shows the students result in detail, in which Registrants (blue) is the number of Registered Students within the selected twelve months period (blue). A student may be counted more than one time, provided the student registered in two or more courses within the chosen curricula and twelve months period. Registrants with activities (green) are registered students that show any activity in NetSpace (enrolls in a course, looks at a calendar, posts something, ,...). Participants (yellow) are registered students that have qualified as a participant in a class. A student may be counted more than one time, provided the student qualified as a participant in two or more courses within the selected curricula and twelve months period. To be eligible as a participant, a student must demonstrate participation by initiating at least one "participating activity" in NetSpace (i.e., assignment, quiz, file download, or access course content). Passed (red) shows the number of registered students who passed the class (received a checkmark in the Instructor Use Only Assign Student Pass Status column in NetSpace or a "P" in the gradebook on Academy Connection). Here you can see a perhaps strange phenomenon, but that due to the ITSA training model has an explanation. As mentioned above, the ITSA training model corresponds to propedeutic cycles (technical, technological, and professional cycle), some students register from the technical cycle, enroll in CCNA1 or CCNP1, and do not continue with the training because they are not promoted to the next training cycle. Given this explanation, the number of CCNA passers is considerably higher than that of CCNP, each year analyzed.

The following analysis is related to student feedback. Feedback is the average of ratings from the Course Feedback forms completed by students at the end of a course for a selected curriculum and 12-month period. The Course Feedback form contains questions about Instructor Rating, and Value to Students, most of the curricula also include questions about Lab Effectiveness, Equipment Access. Since 2018, the survey stopped being applied to the CCNP curriculum, so only CCNA results are shown. However, the same infrastructure of laboratories, classrooms, physical equipment, simulators that are used for CCNA are used for CCNP. Fig. 4 shows the average (maximum value 5.0) of the survey response by curriculum and by year.

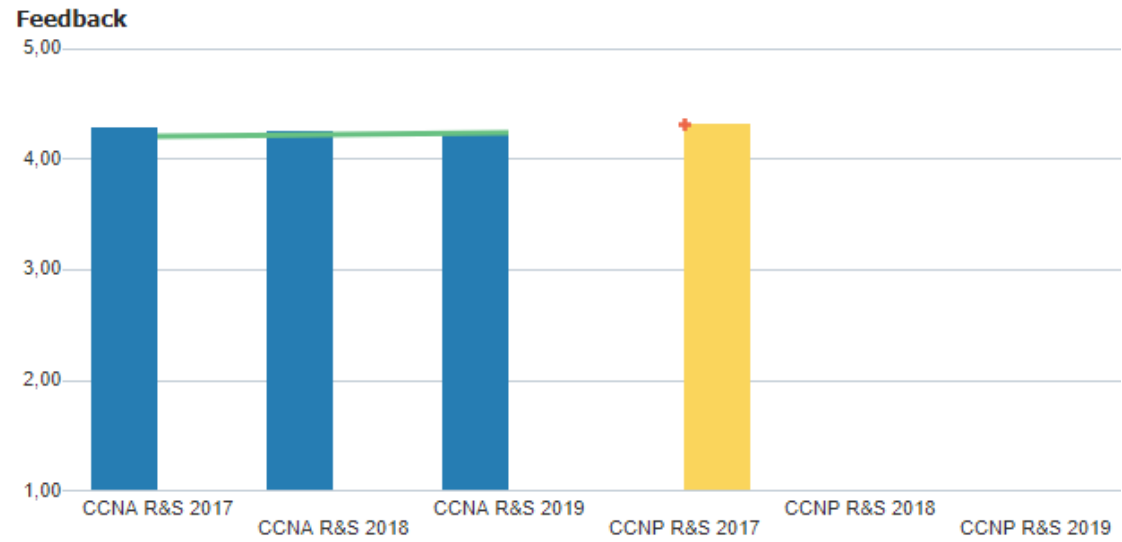

Fig. 4.Feedback Results 


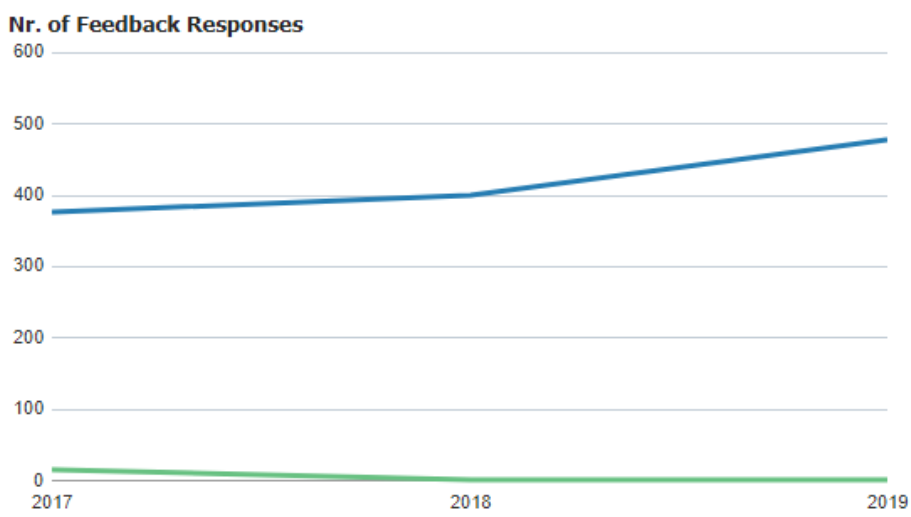

Fig. 5.Number of feedback responses

Fig. 5 shows the relative number of Course Feedback (CF) responses collected across the specified time range by students taking classes in the selected curriculum or curricula. Fig. 6 shows the level of student satisfaction, both from CCNA and CCNP, with access to laboratory equipment and satisfaction with the instructor. Equipment Access reflects whether or not students found the level of access to lab equipment in the class adequate for learning the objectives of the course. Instructor Rating reflects what students report about how much they learned from the instructor and how effectively the instructor emphasized learning through practice As can be seen, in both cases it exceeds the weighting of 4.0, which is very positive, considering that all courses and teachers, which are a considerable number, are evaluated during the study period. The quality of laboratories and teachers is checked at this point
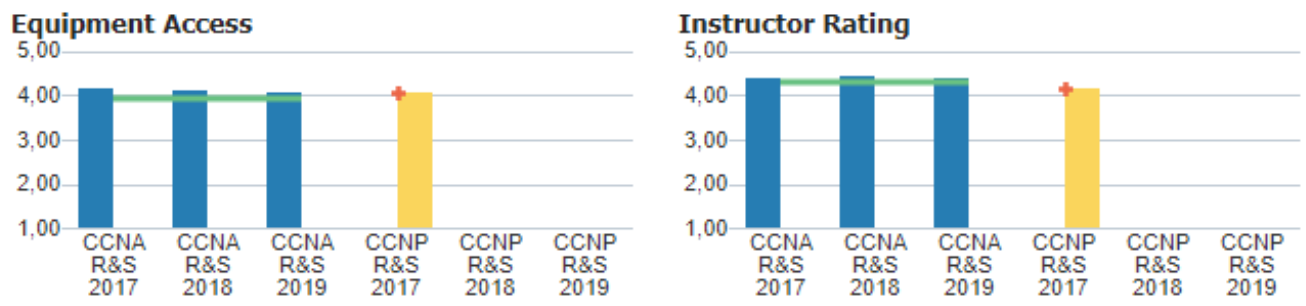

Fig. 6.Level of satisfaction for Equipment access and Instructor rating

Fig. 7 shows the level of student satisfaction with the effectiveness of the laboratories and the value that students place on the academy itself, on the online material, on the importance of training for their future. Professional and regarding whether they would continue studying the following levels offered by the Cisco Networking Academy. Lab Effectiveness reflects what students report about whether the hands-on lab exercises helped them learn the objectives of the course, Value to Students reflects what students report about the value that this training has added to their skill sets and development.
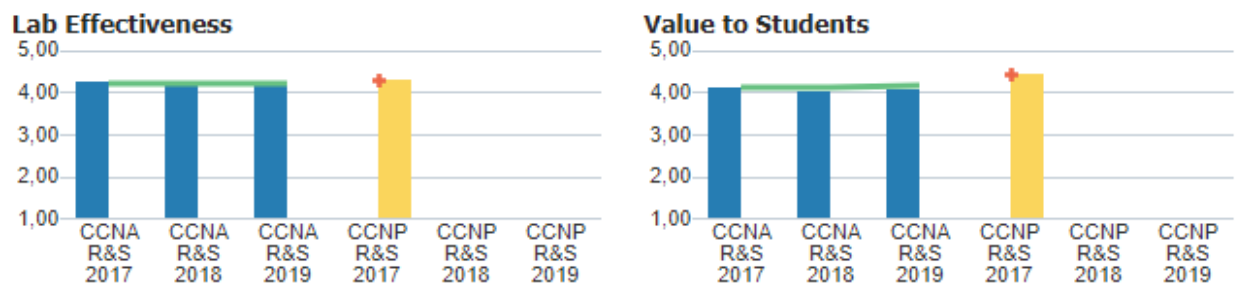

Fig. 7.Level of satisfaction for Lab Effectiveness and Value to Students

The last key success metric to analyze is the student performance, in which it is possible to verify the final exam report and gradebook score (which measures the completion of chapter exams and other activities defined by the instructor). Final Exam is the average of final exam scores for all students. The last attempt is counted. Changes made by instructors afterward in the gradebook are not considered. Fig. 8 shows the final exam report. 


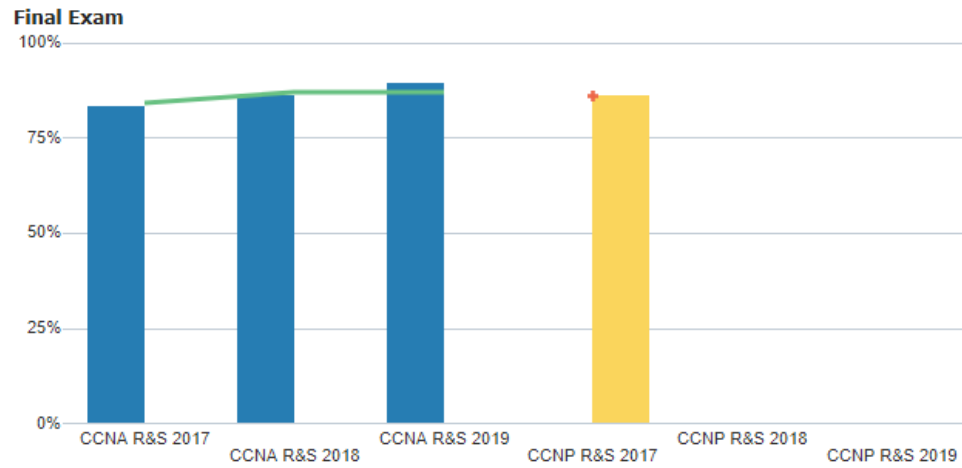

Fig. 8.Final Exam

The final exam averages are above $80 \%$, which is very positive since Cisco demands that it be above $70 \%$. Respectively, the averages of the finals are $83 \%, 86 \%$, and $89 \%$ for the years 2017 , 2018, and 2019. Fig. 9 shows the gradebook score, which is the average of the final scores for all students from class gradebook(s) in NetSpace. Ungraded assignments and assignments that are not completed receive a score of zero (0). This corresponds with the Weighted Percentage for classes that were delivered through Academy Connection.

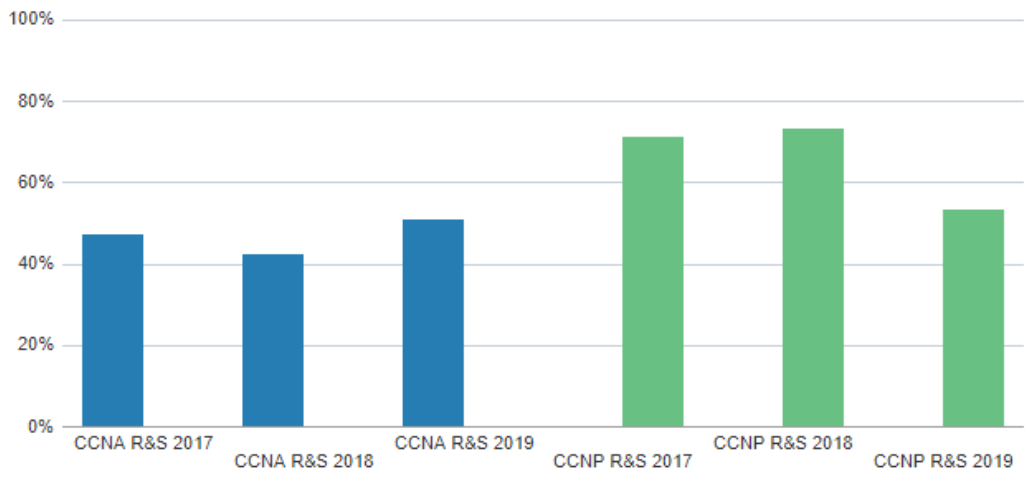

Fig. 9.Gradebook Scores

The previous figure shows another aspect to highlight. For CCNA, some instructors did not require, for specific modules, that students complete the exams online because a Cisco guideline on flexibility in taking exams had been misunderstood. This topic has already been corrected. Some other indicators to analyze are the following. Fig. 10 shows the number of students registered per curriculum. Registrants by Curriculum and Year Line Chart shows the number of registrants in the specified curriculum during selected years. All the values obtained in the analysis of the metrics previously exposed in the figures are summarized in Fig. 11.

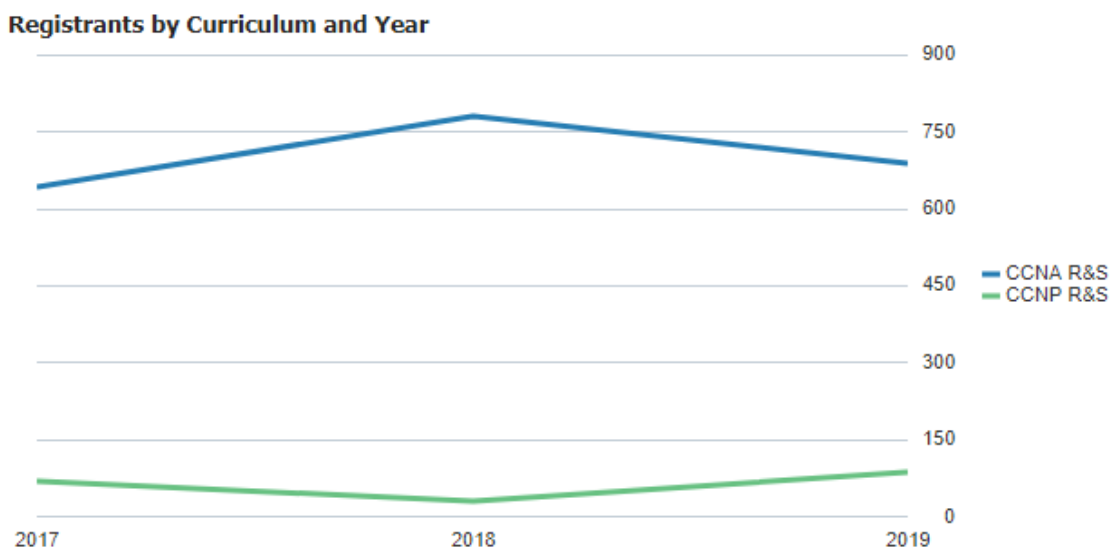

Fig. 10. Registrants by curriculum and year 

Vol. 4, No. 1, July 2020, pp. 21-34

\begin{tabular}{|c|c|c|c|c|c|c|c|c|}
\hline \multirow{4}{*}{$\begin{array}{l}\text { Academy ID } \\
\text { Academy } \\
\text { Curriculum } \\
\text { Year }\end{array}$} & \multicolumn{8}{|c|}{36518} \\
\hline & \multicolumn{8}{|c|}{ INSTITUTO TECNOLOGICO DE SOLEDAD ATLANTICO ITSA } \\
\hline & \multicolumn{4}{|c|}{ CCNA R\&S } & \multicolumn{4}{|c|}{ CCNP R\&S } \\
\hline & 2016 & 2017 & 2018 & 2019 & 2016 & 2017 & 2018 & 2019 \\
\hline ASC ID & 37063 & 37063 & 37063 & 37063 & 37063 & 37063 & 37063 & 37063 \\
\hline N. of registrants by curriculum & 892 & 640 & 781 & 686 & 45 & 68 & 30 & 87 \\
\hline N.e of registrants with activity & 825 & 591 & 662 & 632 & 42 & 66 & 30 & 85 \\
\hline N.o of registrants & 784 & 568 & 646 & 616 & 40 & 64 & 29 & 85 \\
\hline N.o of approved & \begin{tabular}{|l|}
539 \\
\end{tabular} & 350 & 394 & 382 & 39 & 55 & 29 & 59 \\
\hline approval rate & $65 \%$ & $59 \%$ & $60 \%$ & $60 \%$ & $93 \%$ & $83 \%$ & $97 \%$ & $69 \%$ \\
\hline N.e of course feedback responses & 450 & 375 & 398 & 477 & 18 & 14 & 0 & 0 \\
\hline total comments & 4,21 & 4,27 & 4,24 & 4,24 & 4,55 & 4,31 & ND & ND \\
\hline Equipment Access & 3,99 & 4,12 & 4,07 & 4,06 & 4,22 & 4,05 & ND & ND \\
\hline Instructor rating & 4,34 & 4,39 & 4,41 & 4,36 & 4,51 & 4,16 & ND & ND \\
\hline Lab Effectiveness & 4,15 & 4,21 & 4,18 & 4,20 & 4,53 & 4,29 & ND & ND \\
\hline Value to Students & 4,04 & 4,09 & 3,99 & 4,04 & 4,64 & 4,43 & ND & ND \\
\hline Gradebook Score & $42 \%$ & $47 \%$ & $42 \%$ & $51 \%$ & $70 \%$ & $71 \%$ & $73 \%$ & $53 \%$ \\
\hline Final Exam & $79 \%$ & $83 \%$ & $86 \%$ & $89 \%$ & $95 \%$ & $86 \%$ & ND & ND \\
\hline N.o of new registrants & 232 & 174 & 142 & 217 & 3 & 2 & 1 & 0 \\
\hline N. or feedback responses & 309 & 71 & 0 & 1 & 0 & 0 & 0 & 0 \\
\hline N.e of IT-oriented registrants & 222 & 56 & 0 & 1 & 0 & 0 & 0 & 0 \\
\hline N.@ of experienced responses & 811 & 587 & 662 & 632 & 42 & 63 & 29 & 85 \\
\hline N.o experienced registrants & 420 & 296 & 283 & 181 & 33 & 46 & 23 & 50 \\
\hline N. of registrants with activity in voucher classes & 73 & 53 & 34 & 61 & 0 & 0 & 0 & 0 \\
\hline Pass rate in voucher classes & $100,00 \%$ & $85,00 \%$ & $88,44 \%$ & $65,90 \%$ & ND & ND & ND & ND \\
\hline$\%$ of registrants with activity with at least $75 \%$ on final & $71 \%$ & $81 \%$ & $79 \%$ & $86 \%$ & ND & ND & ND & ND \\
\hline Voucher eligible & $71 \%$ & $81 \%$ & $79 \%$ & $64 \%$ & ND & ND & ND & ND \\
\hline Vouchers requested & $3 \%$ & $4 \%$ & $0 \%$ & $5 \%$ & ND & ND & ND & ND \\
\hline N. of registrants - difference year after year & 79 & -252 & 141 & -95 & -73 & 22 & -37 & 56 \\
\hline $\begin{array}{l}\text { N.o of registrants with activity - difference year after } \\
\text { year }\end{array}$ & 93 & -234 & 71 & -30 & -75 & 24 & -36 & 55 \\
\hline N.o of participants - difference year after year & 66 & -216 & 78 & -30 & -77 & 24 & -35 & 56 \\
\hline Approval rate - difference year after year & $-8 \%$ & $-7 \%$ & $1 \%$ & $2 \%$ & $15 \%$ & $-10 \%$ & $13 \%$ & $-27 \%$ \\
\hline N.@ of feedback responses - difference year after year & 17 & -74 & 23 & 79 & -60 & -4 & ND & ND \\
\hline Total feedback responses - difference year after year & 0,12 & 0,07 & $-0,04$ & 0,00 & 0,22 & $-0,24$ & ND & ND \\
\hline Equipment access - difference year after year & 0,05 & 0,12 & $-0,05$ & $-0,01$ & 0,29 & $-0,17$ & ND & ND \\
\hline instructor rating - difference year after year & 0,15 & 0,04 & 0,03 & $-0,05$ & 0,10 & $-0,34$ & ND & ND \\
\hline lab effectiveness - difference year after year & 0,09 & 0,06 & $-0,04$ & 0,02 & 0,22 & $-0,24$ & ND & ND \\
\hline Value to Students - difference year after year & 0,17 & 0,05 & $-0,10$ & 0,05 & 0,22 & $-0,21$ & ND & ND \\
\hline gradebook scores - difference year after year & $0 \%$ & $5 \%$ & $-5 \%$ & $9 \%$ & $-5 \%$ & $0 \%$ & $3 \%$ & $-21 \%$ \\
\hline Final Exam - difference year after year & $-1 \%$ & $4 \%$ & $2 \%$ & $3 \%$ & $5 \%$ & $-9 \%$ & ND & ND \\
\hline pass rate in voucher classes - difference year after year & $21,00 \%$ & $-15,00 \%$ & $10,94 \%$ & $-29,51 \%$ & ND & ND & ND & ND \\
\hline $\begin{array}{l}\text { \% of registrants with activity with at least } 75 \% \text { on final - } \\
\text { difference year after year }\end{array}$ & $10,00 \%$ & $10,00 \%$ & $5,47 \%$ & $0,00 \%$ & ND & ND & ND & ND \\
\hline $\begin{array}{l}\text { N.o of registrants with activity - difference year after } \\
\text { year }\end{array}$ & \begin{tabular}{|c|}
-700 \\
\end{tabular} & -2000 & -2006 & 2849 & $\mathrm{ND}$ & ND & ND & ND \\
\hline Voucher eligible - difference year after year & $19 \%$ & $10 \%$ & $5 \%$ & $-22 \%$ & ND & ND & ND & ND \\
\hline vouchers requested - difference year after year & $-6 \%$ & $1 \%$ & $-4 \%$ & $5 \%$ & ND & ND & ND & ND \\
\hline N.@ of registrants with activity - Country average & 15045 & 16781 & 16804 & 17691 & 1825 & 169 & 298 & 488 \\
\hline N. of registrants - - Country average & 312 & 340 & 356 & 384 & 96 & 50 & 60 & 200 \\
\hline N.o of participants -- Country average & 272 & 292 & 310 & 330 & 71 & 48 & 59 & 190 \\
\hline Approval rate - Country average & $66 \%$ & $67 \%$ & $64 \%$ & $62 \%$ & $59 \%$ & $69 \%$ & $69 \%$ & $69 \%$ \\
\hline Total feedback -- Country average & 4,20 & 4,21 & 4,22 & 4,23 & 4,36 & 4,31 & ND & ND \\
\hline Equipment Access - Country average & 3,91 & 3,93 & 3,94 & 3,94 & 4,06 & 4,05 & ND & ND \\
\hline Instructor rating - Country average & 4,31 & 4,30 & 4,32 & 4,32 & 4,33 & 4,16 & ND & ND \\
\hline Lab Effectiveness - Country average & 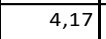 & 4,19 & 4,20 & 4,21 & 4,38 & 4,29 & ND & ND \\
\hline Value to students - Country average & 4,14 & 4,13 & 4,13 & 4,15 & 4,38 & 4,43 & ND & ND \\
\hline Final Exam - Country average & $84 \%$ & $84 \%$ & $87 \%$ & $87 \%$ & $93 \%$ & $86 \%$ & ND & ND \\
\hline N.@ of registrants in voucher classes - Country average & 32 & 30 & 36 & 40 & ND & ND & ND & ND \\
\hline Approval rate in voucher classes - Country average & $75,00 \%$ & $82,00 \%$ & $73,00 \%$ & $70,00 \%$ & ND & ND & ND & ND \\
\hline $\begin{array}{l}\text { \% of registrants with activity with at least } 75 \% \text { on final - } \\
\text { Country average }\end{array}$ & $68,00 \%$ & $64,00 \%$ & $68,00 \%$ & $57,00 \%$ & ND & ND & ND & ND \\
\hline Voucher eligible -- Country average & $63 \%$ & $61 \%$ & $62 \%$ & $51 \%$ & ND & ND & ND & ND \\
\hline Voucher requested - Country average & $16 \%$ & $19 \%$ & $9 \%$ & $11 \%$ & $\mathrm{ND}$ & $\mathrm{ND}$ & ND & ND \\
\hline
\end{tabular}

Fig. 11. Details Table 


\subsection{Data analytics from a CCNA module.}

This last section shows the data analytics calculated by Cisco for a specific CCNA course, more precisely the final module called Connecting Networks. In this module, students already have previous knowledge acquired thanks to the 3 previous modules, being on the verge of finishing their training and thus being able to take the certification exam. Fig 12 shows the interaction that the students have had with the Cisco moodle platform (participation in forums, reading the material online, taking online exams):

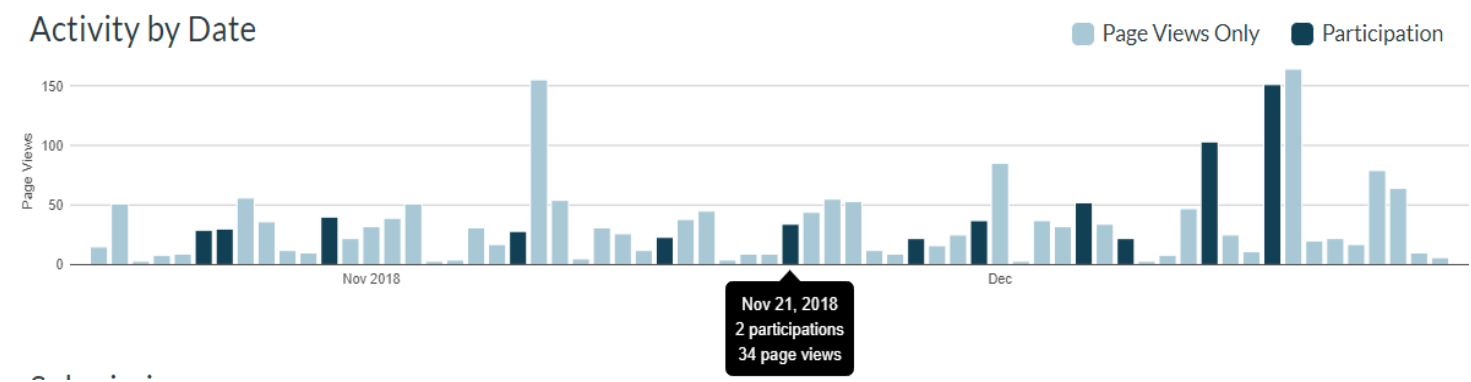

Fig. 12. Interaction of the studens with the platform.

Fig. 13 shows the percentage of student compliance with respect to the presentation of online exams. As can be seen, students have a high average of compliance, given their special interest in preparing adequately to obtain their certification:

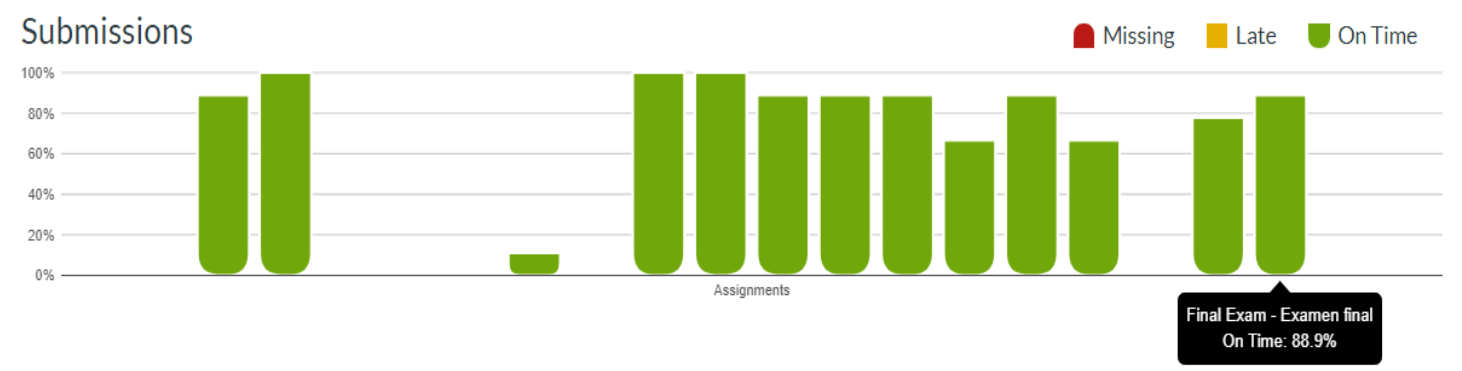

Fig. 13. Submissions of online exams.

Fig. 14 shows the tabulated general course data. Only one student did not complete his activities (for reasons of force majeure he had to withdraw). The rest of the students successfully completed their training cycle, and subsequently passed their certification exam. Today they are working in important companies in the local productive sector.

\begin{tabular}{|c|c|c|c|c|c|c|c|}
\hline Student • & Page Views & Participations & Submissions & On Time & Late & Missing & Current Score \\
\hline Andrea Carolina Gonzalez Amaris & 125 & 0 & 11 & 11 & 0 & 0 & $82.01 \%$ \\
\hline Jossie Esteban Coronell Bolivar & 139 & 0 & 11 & 11 & 0 & 0 & $86.31 \%$ \\
\hline José Carlos Rudas Garcia & 144 & 0 & 11 & 11 & 0 & 0 & $65.27 \%$ \\
\hline Andres Guzman & 107 & 0 & 11 & 11 & 0 & 0 & $91.85 \%$ \\
\hline Jairo Luis Vargas Orozco & 63 & 1 & 12 & 12 & 0 & 0 & $90.56 \%$ \\
\hline Oscar David Pozzo Ortiz & 238 & 10 & 12 & 12 & 0 & 0 & $92.37 \%$ \\
\hline Cesar Salas & 130 & 0 & 4 & 4 & 0 & 0 & $53.32 \%$ \\
\hline Albert Antony Celin Salcedo & 199 & 2 & 11 & 11 & 0 & 0 & $90.24 \%$ \\
\hline Jorge Enrique Jaramillo Zapata & 82 & 0 & 12 & 12 & 0 & 0 & $92.35 \%$ \\
\hline
\end{tabular}

Fig. 14. Final statistics per student. 


\section{Conclusion}

Technology is potent when combined with Education. Cisco Networking Academy was born 23 years ago, with the primary objective of teaching some companies to build their networks. The Networking Academy quickly grew from a single school to become an ever-expanding community of students, educators, employers, Cisco employees, and customers. Now, the academy is present in 180 countries around the world. According to the Cisco Networking Academy web site, the University impacts the lives of 10.9 million students in all continents. The number of educators is 26.500, spread over 12.100 academies.

In our local environment, throughout these years of validity of the academy at ITSA, the CCNA and CCNP curriculum has been integrated into the curriculum of undergraduate training programs, offering low-income students and outsiders who take the courses such as extension programs, a high-quality training, that enhances their skills, and that has transformed their lives, since the vast majority of students work in various companies in the productive sector, and even in companies directly associated with Cisco, improving their quality of life substantially.

As can be seen in the metrics of success analyzed, the number of CCNA and CCNP students who have reached full training and certification as such is high. As future work, strategies should be designed to promote CCNP, increase the number of registered and certified students. It is expected to do a factor analysis by clusters to identify better groups in the community on which to act in a better way. Also, perform a regression analysis to verify the relationship between variables. Finally, to carry out an additional study in which more Cisco Networking Academy programs are included.

\section{References}

[1] D. del programa I. T.- ITSA, "Documento_Maestro_Renovacion_Ingenieria_Telematica." ITSA, Barranquilla, p. 428, 2018.

[2] J. T. Behrens, R. J. Mislevy, K. E. Dicerbo, and R. Levy, "Evidence Centered Design For Learning And Assessment In The Digital World," in Technology-Based Assessments for 21st Century Skills, 2012.

[3] Cisco Networking Academy, "Cisco Networking Academy," 2015, 2015. [Online]. Available: http://www.cisco.com/web/learning/netacad/index.html.

[4] N. Moss and A. Smith, "Large scale delivery of Cisco Networking Academy program by blended distance learning," in 6th International Conference on Networking and Services, ICNS 2010, Includes LMPCNA 2010; INTENSIVE 2010, 2010.

[5] J. Janitor, F. Jakab, and K. Kniewald, "Visual learning tools for teaching/learning computer networks: Cisco Networking Academy and packet tracer," in 6th International Conference on Networking and Services, ICNS 2010, Includes LMPCNA 2010; INTENSIVE 2010, 2010.

[6] A. Zhamanov and Z. Sakhiyeva, "Implementing flipped classroom and gamification teaching methods into computer networks subject, by using cisco networking academy," in Proceedings of the 2015 12th International Conference on Electronics Computer and Computation, ICECCO 2015, 2016.

[7] A. Zhamanov, S. M. Yoo, Z. Sakhiyeva, and M. Zhaparov, "Implementation and evaluation of flipped classroom as IoT element into learning process of computer network education," Int. J. Inf. Commun. Technol. Educ., 2018.

[8] H. Cakır and B. A. Bichelmeyer, "Effects of teacher professional characteristics on student achievement: an investigation in blended learning environment with standards-based curriculum," Interact. Learn. Environ., 2016.

[9] J. T. Behrens, D. Frezzo, R. Mislevy, M. Kroopnick, and D. Wise, "Structural, Functional, and Semiotic Symmetries in Simulation-Based Games and Assessments," in Assessment of Problem Solving Using Simulations, 2018.

[10]D. Petcu, B. Iancu, A. Peculea, V. Dadarlat, and E. Cebuc, "Integrating Cisco Packet Tracer with Moodle platform: Support for teaching and automatic evaluation," in Proceedings - RoEduNet IEEE International Conference, 2013. 
[11]A. Mikroyannidis, A. Gomez-Goiri, A. Smith, and J. Domingue, "Online experimentation and interactive learning resources for teaching network engineering," in IEEE Global Engineering Education Conference, EDUCON, 2017.

[12]N. Moss and R. Seaton, "Development of a vendor practice-based distance based learning programme," in Laboratories for the 21st Century in STEM Higher Education: A Compendium of Current UK Practice and an Insight into Future Directions for Laboratory-Based Teaching and Learning, 2013.

[13]B. R. Gottwig, "The impact of high school principal's technology leadership on the sustainability of corporate sponsored information communication technology curriculum.," Diss. Abstr. Int. Sect. A Humanit. Soc. Sci., 2014.

[14]J. F. van Niekerk and K. L. Thomson, "Evaluating the cisco networking academy program's instructional model against bloom's taxonomy for the purpose of information security education for organizational end-users," IFIP Adv. Inf. Commun. Technol., 2010.

[15]K. Kleinová, P. Fecil'Ak, and F. Jakab, "Networking academy - Innovation in education," in ICETA 2012 - 10th IEEE International Conference on Emerging eLearning Technologies and Applications, Proceedings, 2012.

[16]G. Jourjon et al., "FORGE Toolkit: Leveraging Distributed Systems in eLearning Platforms," IEEE Trans. Emerg. Top. Comput., 2017.

[17]R. Ab Rahman, M. M. Md Zan, H. Z. Abidin, M. Kassim, and H. C. K. Che Ku Yahaya, "Impact of globalization and industry on engineering education at higher learning education in Malaysia," in 2010 IEEE Transforming Engineering Education: Creating Interdisciplinary Skills for Complex Global Environments, 2010.

[18]K. Kleinová, P. Fecilak, F. Jakab, and Z. Szalay, "Transforming Vocational education in Slovakia," in ICETA 2011 - 9th IEEE International Conference on Emerging eLearning Technologies and Applications, Proceedings, 2011.

[19] O. Yekela, K. L. Thomson, and J. van Niekerk, "Assessing the effectiveness of the Cisco Networking Academy Program in developing countries," in IFIP Advances in Information and Communication Technology, 2017.

[20] J. Villalba, "Cisco Networking Academy 'Corporate Social Responsibility," Rev. Científica la UCSA, 2017.

[21]E. Z. Red, "Students' Performance and Satisfaction with the Cisco Academy Networking Program (Computer Networking 1): Basis for a Proposed Pedagogical Action in Blended Learning," IAMURE Int. J. Multidiscip. Res., 2012.

[22] R. Hernandez, C. Fernandez, and M. Baptista, Metodología de la investigación. 2010.

[23]R. Walpole, R. Myers, S. Myers, and K. Ye, Probabilidad y Estadística para Ingenierías y Ciencias, Novena Edición. México: Pearson, 2012. 